\title{
Comparison of Continuous Assessment (CA) and Examination Scores in an English Speech Work Class
}

\author{
Iyabode Omolara Akewo DANIEL, PhD \\ English Unit, School of Arts and Social Sciences \\ National Open University of Nigeria \\ Victoria Island, Lagos, Nigeria \\ E-mail: akewoauthe@gmail.com
}

Received: 02-07- 2012

doi:10.7575/ijalel.v.1n.6p.92
Accepted: 04-08- 2012

Published: 01-11- 2012

URL: http://dx.doi.org/10.7575/ijalel.v.1n.6p.92

\begin{abstract}
English language oral teaching and testing has usually been a problematic issue in the Nigerian educational system. This study thus examines the way Continuous Assessment (CA) and examination results compare in the ENG 121 English orals practical class in FCE, Okene. This is to assess the impact of the innovative pragmatic approach of continuous practice of pronunciation employed by the course lecturer. The performance levels of the candidates are ranked on a scale of 1-10. A frequency and percentage comparative ranking of the scores is done. A tabular and graphic presentation of the scores reveals the students' performance is generally above average, indicating the success of the pragmatic approach. Nevertheless, a more favourable performance in the CA than in the examination is observed. The paper concludes that the innovative approach greatly helped the students to improve on their performance in spoken English. It thus recommends, among other things, that pragmatic teaching procedure should be constantly employed in teaching Nigerian students to the end of Nigeria attaining her true position in the comity of nations.
\end{abstract}

Key words: English orals, Speech work class, Nigerian education system, functional education, innovation, CA and examination scores

\section{Introduction}

It is stating the obvious to say that the English language plays a pivotal role in Nigeria's national life (Oderinde, 1979; Osakwe, 2005; Oyeleye, 1990). However, the way many teachers of English tend to avoid practical teaching of the English language pronunciation is disturbing (Daniel, 2011). One of the Nigerian educational objectives is that the educational process should enable her citizens to acquire "competencies necessary for self-reliance" (Federal Republic of Nigeria, 2004: 8). The suggestion here is that the educational process should be about the learner and making the learner effective in skill(s) learnt (Afemikhe, 2008; Obanya, 1979). Effectiveness of the learner thus connotes the functionality of an educational process. Avoidance of oral English teaching in a country where the English language is so vital to most national activities does not portray a functional educational process. It would be tantamount to self-deception to regard products of such an educational process as effective. It thus becomes pertinent to try new ideas in the Nigerian English speech work class.

Innovation is usually perceived as the introduction of novel ideas into old processes. To innovate means to inject "new ideas, methods, etc." into how activities in some endeavours are carried out (Chambers Study Dictionary, 2002: 396). Bishop (1986: 5) sees innovation as "a deliberate intrusion into the fabric of culture." Afemikhe (2008) asserts that innovation in education is prerequisite for educational advancement if the Nigerian education system would contribute effectively to her development. In this wise, continuous assessment (CA) is an innovation the government introduced to help improve students' performance through a continuous monitoring of their achievement in the course of undergoing an educational programme. In the Open and Distance Learning as exemplified by the National Open University of Nigeria, this same continuous assessment practice is called Tutor Marked Assignment (TMA). The expectation is that, with the introduction of this new way of teaching and testing as part of the educational process, the end result should be greater effectiveness and functionality among Nigerian citizens in their different areas of endeavour. 
Conversely, findings point to the fact that this innovation had not always been successful in attaining the fundamental goal for which it was introduced into the Nigerian educational system (Daniel, 2008). The perceived failure of the CA innovation in Nigeria may, however, not be inherent but due largely to a macro systemic decay that intrudes into the educational process. The sad reality of the certificate-fixated educational system in Nigeria has led to all kinds of subversive activities by those that should safe-guard the integrity of the educational process.

Various studies have compared students' performance in different subjects, incorporating diverse variables. Standardised tests are the more common basis of such comparisons. Daniel (2008) compared students' achievement in mathematics in WAEC and NECO SSCEs in Nigeria. His findings imply that students' performances in the two examinations are slightly different from one another and can therefore not be substituted for each other. He accounts for the dissimilarity as rooted in the disparity in the questions the examination bodies give to students as well as their different grading systems.

Nonetheless, studies conducted into the results of CA comparisons with those of examinations have shown different levels of relationship between them. For instance, some studies found low, non-significant relationship between CA scores and examination scores (e.g. Hassan \& Adeyanju, 1998; Lawal, 1999) whereas Attah and Binda (2001) found high significant relationship between CA and examination in a number of school subjects. Njoku (2001) investigated the relationship between CA and NCE education courses at the FCE, Okene and found a generally low relationship between performance in CA and examination. Some of the reasons for these differing results include such factors as differences in the quality of tests and examination, procedures for scoring, leniency in the conduct of CA, and doubtful integrity of some teachers.

This study is limited to the year one practical course, ENG 121, in the Department of English of the Federal College of Education, Okene located in Kogi State, Nigeria. The chosen device is a comparison of the continuous assessment (CA) and semester examination scores of the students. The expectation is that these will reveal the comparative effectiveness of the pragmatic teaching process adopted by the teacher in $\mathrm{CA}$ and examination situations.

\subsection{Objective of the Study}

This study compares (graphically) students' performance in CA and examination practical tests in ENG 121 across grades in the NCE I English class for 2007/2008 session in FCE, Okene. This is to show the consistency in the performance of students across testing procedures in demonstration of their mastery of the innovative practical teaching system employed by the teacher in the English speech work class.

\subsection{Research Question}

How do students' ENG 121 practical tests CA and examination scores compare (graphically) across grades as a demonstration of the application of the practical teaching procedure employed in the speech work class?

\section{Methodology}

\subsection{Population and Sample}

A total of 84 students took the examination while only 80 students took the CA. The disparity arises from the absence of some of the students during the CA. However, the absence of the four candidates in the CA is not considered significant enough to undermine the final result. Even though ENG 121 is an elective course, all the students in NCE I usually take it. This is probably due to their non awareness of its elective status or because it is compulsory for them by default being their first year in the National Certificate of Education (NCE) programme. In essence, all the students in the ENG 121 class, including repeaters, for 2007/2008 session make up the population for the study. Consequently, the scores of all the 80 and 84 candidates, which participated in the CA and the examination respectively, are used as data sample.

\subsection{Data Collection}

The data used are the CA test and examination results of the ENG 121 class for 2007/2008 session. These serve as the output of the innovative teaching procedure of continuous practical speech work in the class. As required by the National Commission for Colleges of Education (NCCE) regulation (the monitoring body of colleges of education), 100 percent is the requisite examination result at the end of a semester in a particular course. The 60 percent of the examination is expected to be made up of an actual sit in examination while the remaining 40 percent is made up of CA. This was done in this case. For the CA and the examination, 10 percent out of the required marks are the maximum scores for the practical sections of the two tests while the remaining percentage was in the written form. It could be argued that for a practical course, this 20 percent out of 100 percent is quite low. This is

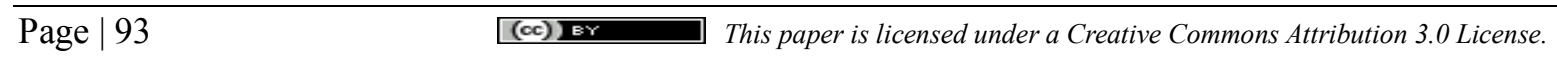




\section{International Journal of Applied Linguistics \& English Literature}

ISSN 2200-3592 (Print), ISSN 2200-3452 (Online)

Vol. 1 No. 6; November 2012

agreeable; especially when one considers the fact that the course is tagged 'Speech Work' and the major part of the course content involves a lot of practical work.

Nonetheless, it needs to be pointed out that, as observed by Oderinde (1979), practical oral test should be carried out by one examiner. For a large class involved here, this could become very tasking, if not suicidal, for the teacher. For this reason, a middle point of wide practical practice and limited but effective practical testing was chosen as a pragmatic option. Therefore, the data analysed in this paper are the 20 percent total practical result from the CA and semester examination tests of the population class. It needs be pointed out, however, that only the initial range scores assigned to the raw scores are used for the analysis as the raw scores in the two tests were submitted to the College as regulation requires.

\subsection{Instrument of Data Analysis}

A comparative graphical analysis is adopted in this study. The results from the two tests are compared, using descriptive statistics and line graph. The scores are graded on frequency count. This is to make it possible to ascertain the students' level of performance on a scale of 1-10.

\section{Data Analysis}

Table 1. Frequency and Percentage of Students' Performance Level in Speech Work

\begin{tabular}{lll}
\hline Performance Level & \multicolumn{2}{l}{ Frequency/Percentage of Students } \\
\cline { 2 - 3 } & CA & EXAM \\
\hline 1 & $0(0.0)$ & $1(1.19)$ \\
2 & $1(1.25)$ & $7(8.33)$ \\
3 & $1(1.25)$ & $4(4.76)$ \\
4 & $5(6.25)$ & $17(20.24)$ \\
5 & $10(12.25)$ & $10(11.90)$ \\
6 & $17(21.25)$ & $23(27.38)$ \\
7 & $15(18.75)$ & $12(14.29)$ \\
8 & $15(18.75)$ & $9(10.91)$ \\
9 & $12(15.00)$ & $0(0.0)$ \\
10 & $4(5.00)$ & $1(1.19)$ \\
\hline Total & $80(100)$ & $84(100)$ \\
\hline
\end{tabular}

*Percentage in brackets

Table 2. Frequency and Percentage of Students Performance Level in Descending Order

\begin{tabular}{llll}
\hline CA Scores & Frequency $(\%)$ & Exam Scores & Frequency $(\%)$ \\
\hline 6 & $17(21.25)$ & 6 & $23(27.38)$ \\
7 & $15(18.75)$ & 4 & $17(20.24)$ \\
8 & $15(18.75)$ & 7 & $12(14.29)$ \\
9 & $12(15.00)$ & 5 & $10(11.90)$ \\
5 & $10(12.25)$ & 8 & $9(10.91)$ \\
4 & $5(6.25)$ & 2 & $7(8.33)$ \\
10 & $4(5.00)$ & 3 & $4(4.76)$ \\
3 & $1(1.25)$ & 10 & $1(1.19)$ \\
2 & $1(1.25)$ & 1 & $1(1.19)$ \\
1 & $0(0.0)$ & 9 & $0(0.0)$ \\
\hline Total & $80(100)$ & Total & $84(100)$ \\
\hline
\end{tabular}

*Percentage in brackets 
First and foremost, it is obvious, as it is common with students in FCE, Okene, that some that missed the class test still went ahead to participate in the examination even though it means they have failed technically, whatever their examination scores. This accounts for the differential totals in the examination and CA sample population: a difference of four candidates in all. By the examiner's records, only one candidate was absent from the CA oral test due to ill-health, though this is not presented in the data as it is not considered significant to the possible findings in the research.

The tables appear self-explanatory. From Table 1, we find the performance level of students on the scale of 1-10 while Table 2 presents the frequency arranged in descending order of scores (from the highest to the lowest) in terms of how frequently the scores were obtained in the CA test and the semester examination. The percentages for the scores' frequency are presented in brackets for easier deciphering of the performance levels. The comparison of the CA and examination results is represented graphically below.

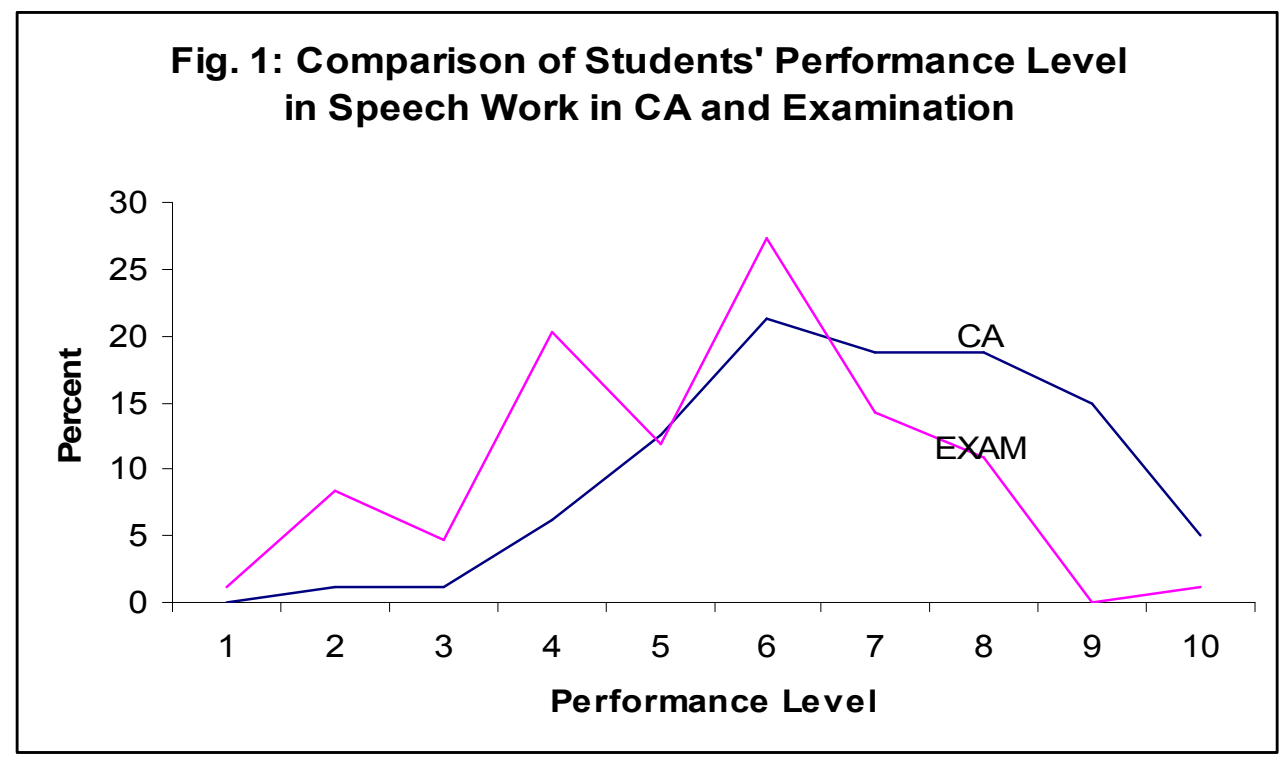

The line graph (Fig. 1) above shows a diagrammatic representation of Table 2. It reveals that the class maintains an average mark in the range of 5-7 in both the CA and semester examination tests. More of the candidates, however, seem to have lower marks at the range of 1-4 in the examinations whereas a lesser number have this in the CA test where most of them appear to have higher scores in the range of 7-10. The CA scores in the graph thus indicate that the students' have a more favourable performance in the CA than in the examination. This is further discussed in the next section.

\section{Discussion of Findings}

The score of six over ten seems to be the average mark that is maintained by most of the candidates in the CA and the examination as the tabular and graphical representation of the performance level shows in both frequency and percentage counts; it marks the peak performance level for the two tests. It suggests that the tests could be seen as valid and reliable (Obanya, 1979a) as the consistency of the candidates appear obvious in the two tests. Nonetheless, it is of interest that the second highest score in the examination is four while seven and eight tied in the CA test. Could it be said that there was probably lower test anxiety during the CA than was obtainable during the semester examination thus allowing for a more favourable performance level for the students? One would have expected a better performance in the examination considering the way students tend to take it a lot more seriously in terms of preparation coupled with the fact that they had undergone the class test before it, thereby making the CA test a kind of dress-rehearsal before the examination. Nevertheless, the results indicate that their performance slid steeply after attaining a very high level of performance at six in the examination while it suggests a gradual increase of their attainment level in the CA test. It needs be pointed out that the course lecturer/writer of this paper conducting the test herself makes the issue of teacher integrity a non-factor in the favourable performance of the candidates in the CA (cf. Njoku, 2011).

The candidates' attainment of zero occurrence of one in the test and zero occurrence of nine in the examination is also surprising. Nevertheless, the issue of examination tension could again account for this. Moreover, the number 
of those absent for the initial test that participated in the examination could also have had some slight impact on the lower performance level in some of the higher scores in the examination as their absence from the CA test could have made them have low marks in the examination as some of these are also regular absentees from the lecture classes. The significance level of their impact still appears negligible, however. All the same, higher anxiety level is found to be expressed by some of the candidates during the examination than during the CA tests. The absentee group could have generally fallen into this category and thus increase the chance of poorer performance by those in the absentee group.

Furthermore, it is possible that the students having to take the written and oral examinations on different days during the CA test while they took the written and practical oral examinations on the same day could also account for this slight disparity in the performance on the higher scores. However, the difference in the effect of the examination timing may not be regarded as significantly high enough to create two different examination days for the course. The attempt to allow for more time in terms of the students having a break from any other examination immediately after ENG 121 could significantly lower the students' anxiety during the oral examination as they are usually anxious to get to another examination venue immediately after the oral examination. One thus hopes that policy makers in tertiary institutions would find it necessary to treat the phonetics practical class with the same seriousness that other science subjects are treated and allocated full day practical testing period on examination timetables.

In the final analysis, the graphical representation of the two points of joining at the 6 to $6 \frac{1}{2}$ performance levels in Fig. 1 shows the meeting points of the two tests on the higher level of performance by the candidates, thus indicating an above average performance on the two tests. This is quite encouraging, signifying a positive impact of the innovation of the communicative pragmatism on the students' performance in the ENG 121 class. This agrees with some of the previous findings that there is a significant relationship between CA and examination. However, Njoku's (2001) finding of low relationship between CA and examination could only be linked to this study in so far as the effect of the absentee group on the overall result. Nevertheless, as previously stated, this does not have a significant effect on the result. Therefore, in agreement with Attah and Binda (2001), the finding in this study reveals that there is a significant relationship between CA and examination. The implication is that a practically oriented course practically taught would have a performance level that is consistent in all tests and contexts. This shows that pragmatism can succeed in the Nigerian educational system, especially at the tertiary level, and add value to her developmental drive.

Oderinde (1979) notes that the way spoken English is generally taught has taken cognizance of the fact that students need to master it for the purposes of social interaction. This was not much seen in the entry behaviour of the students used as the population sample for this study. One may, therefore, regard such sweeping statements as wishful thinking. Daniel (2011) asserts that bad training of teachers of English in terms of their own teachers' avoidance of oral English teaching and testing in the class could be responsible for this state of affairs. Alo (2005) has, therefore, suggested the incorporation of Halliday's Systemic Grammar into the teaching process of the average pre-tertiary English teacher in Nigeria. In our view, theories are good academic exercise for the base of higher educational teaching but they may not always have the answer to what needs to be done to get results. That the sociological base of Systemic Grammar has always made it attractive for educational linguistics as Christie (1989) argues so beautifully is not in doubt, but the snag is that theories that do not leave the armchair do not get the work done.

In this wise, the attempt to functionally introduce students to their need to overcome their needless fear of the English sound system is more important. Overcoming the apparently daunting English phonetics and phonology through repeated practice could move the students towards proper mastery of the spoken English in Nigeria as shown by their more positive response to the pragmatic approach in terms of better performance as shown in this study. Beyond theories, the pragmatic approach seems a lot more reasonable. And in an institution focused on training teachers for the primary education level like the NCE, facing the teaching of oral English squarely appears a proper way to create effective English language teachers. This could be applied to any tertiary teacher training institution for profitable production of effective teachers of the English language in our pre-tertiary schools.

As shown by the results in Tables $1 \& 2$ and Fig. 1, the fact that the students have had series of practice enabled them to average a reasonable performance level despite their disadvantaged entry behaviour. Apparently, examination circumstances have not always been the best judge of students' ability, but examination is clearly, for now, the most objective and accessible. The hope however is that it will prove to also be the base of more stimulating enquiry to improve the self by the students. They were usually reminded in the class that their learning 
and mastering the English language is not just to pass the examination or to avoid repeating the course, but essentially, to function effectively in the wider world where English has become the ticket to many important existential conditions in the modern world.

On this note, Oderinde's (1979) postulation becomes relevant and uncanny. Christie's (1989) and van Dijk's (1993) identification of language as power index in social relationships is also very relevant here. Mastery of the English language for students in a teachers' college is however more significant than just for the sake of functioning within the social power paradigm; it is what makes them effective educators of the English language and thus part of making the Nigerian educational system succeed. This, one hopes this little experiment has succeeded in contributing to while propelling the student teachers of English to enquire further in their chosen field as they seek for relevance in a fast changing world.

\section{Conclusion}

The study set out to present a report of an innovative experiment attempted by a lecturer of English in the FCE, Okene. The results show that the students' CA test and examination that were compared point to an apparent above average performance level by the students in NCE 1 in their English language practical course. The paper thus concludes that this pragmatic approach to the teaching of English should prove more effective to create functional citizens and educators towards making the Nigerian educational system more functionally impactful within the Nigerian socio-cultural milieu.

\section{Recommendations}

Firstly, in our view, pragmatism is what the Nigerian educational system requires if it will ever catch up with the rest of the world, Vision 20:20:20 notwithstanding. This is more so when one considers the claim by a teacher of the English language at the 2011 Nigeria English Studies Association's meeting during its annual conference that she has not mastered the use of the computer. This is surprising in that she is expected to teach students that have advanced in most cases in the use of Information and Communication Technology (ICT) equipment (cf. Daniel, 2012). Many young people of these days talk of 'pinging' and the rest of them. Many of the students this teacher is also expected to teach are good at browsing the internet, using i-phones and i-pads. In these days of such a fast changing and technologically dominated world, a teacher that decides to stay behind will be left behind. How will such a teacher effectively guide students in the practical mastery of English orals through the use of software considering that there now exist e-laboratories for language teaching? One thinks that a pragmatic teacher should be able to give practical academic leadership to their students to maintain relevance in the educational sector. The effectiveness of the application of innovativeness in practical teaching and demonstrable acquisition of spoken English skills in the training of students in the English speech work class by the lecturer in this study thus demonstrates the wisdom of this practical approach to the teaching of the English orals. This can be replicated in any other subject area for that matter to advance Nigeria's developmental drive.

Secondly, certificate fixation within the Nigerian educational system must give way to practical demonstration of abilities as this has not really enabled the country to make as much impact as it should. Practical ability, as demonstrated by students, should be the rating standard. This may also help reduce the current desperation to obtain certificates by all means. As the students in this study had to practically demonstrate their ability to speak the English language to earn the required credits, they had no choice than to be participatory in the class. This we found has a significant effect of astronomically improving on their demonstrable skills when compared to their poor entry behaviour. This should thus be a lesson to educators that pragmatic education is better for social advancement within the Nigerian society.

Thirdly, the essentiality of the English language to the modern techno-dominated world also requires the application of practical approach to the teaching of the English language if Nigeria will gain relevance and currency. Countries like India and Brazil, which were once regarded as third world countries, are apparently making waves in the world today through their practical inputs in the world of modern technology and economics. Arm chair critics do not make much impact these days because day dreaming is no longer the name of the game. It is a world determined by the value you add, which in turn determines your worth. The Nigerian educational system must thus go the way of innovative practicality as this study has demonstrated. Language as an essential pivot in the world of politics and the ICT can show the way forward through practical demonstration of ability as shown in this study. Nigerian English students will definitely learn and properly master the English language, if they are practically taught. Education that has relevance in today's world is that which develops demonstrable ability. The students pragmatically taught in this study eventually demonstrated their ability to use the English language practically as their results in the CA and the examination show.

\footnotetext{
Page | $97 \quad$ This paper is licensed under a Creative Commons Attribution 3.0 License.
} 
Finally, we have tried to use this study to show that pragmatic teaching of the English speech work has advanced the practical ability of the students of the English language in mastering their ability at speaking the English language for effective communication purposes. Teachers of English thus need to make their teaching of the English language or even literature-in-English practical and relevant to their students to take them to a higher level of the effective usage of the English language in a globalised world.

\section{References}

Afemikhe, O. A. (2008). Functionality and innovation in Nigerian education: Reflections of an evaluator. Lead paper presented at the 4th Annual Conference of the School of Education, Federal College of Education, Okene. Alo, M. A. (2005). Revisiting issues in English use and usage in Nigeria: Implications for the ESL classroom. Journal of Nigeria English Studies Association, 11 (1), 114-130

Attah, B. G. \& Binda, I. S. (2001). A correlation analysis of continuous assessment scores and terminal examination scores in mathematics. A paper presented at the 18th Annual Conference of the Nigerian Academy of Education held at the University of Jos, Jos 12th-16th November.

Bishop, G. (1986). Innovation in education. London and Basingstoke: Macmillan Publishers Ltd.

Chambers Study Dictionary. (2002). Edinburgh: Chambers Harrap Publishers Ltd.

Christie, F. (1989). Foreword. In MAK Halliday's Spoken and written language (2nd ed). Oxford: Oxford University Press, v-xii.

Daniel, F. (2008). Comparative analysis of examination questions and achievement levels of students in WAEC and NECO General Mathematics SSCE. PhD Thesis, University of Benin, Benin City, Nigeria.

Daniel, I. O. (2011). Introductory phonetics and phonology of English. Newcastle upon Tyne: Cambridge Scholars Publishing.

Daniel, I. O. (2012). Evolutionary trends in English language material design. Research Journal in Organizational Psychology and Educational study 1(1) January, 13-18

Federal Republic of Nigeria. (2004). National policy on education (4th ed). Lagos. NERDC Press.

Hassan, H. \& Adeyanju, G. A. (1998). The predictive validity of performance in continuous assessment in some Senior School Certificate Examination. The Nigerian Teacher Today, 6 (1). 174-180.

Lawal, J. (1999). A study of the level of correlation between continuous assessment scores and students' examination scores. The Nigerian Teacher Today, 5 (1 \& 2). August, 117-121.

Njoku, N. F. (2001). Relationship between CA and NCE education courses: A case study of the FCE, Okene. A paper presented at the 16th annual congress of Nigerian Academy of Education held at the University of Jos, Jos. 12th-16th November.

Obanya, P. A. I. (1979). A suggested evaluation model for English language teaching. In E. Ubahakwe (Ed.) The teaching of English studies: Readings for colleges and universities, (pp. 340-348). Ibadan: Ibadan University Press.

Obanya, P. A. I. (1979a). Types and functions of tests in English language teaching. In E. Ubahakwe (Ed.) The teaching of English studies: Readings for colleges and universities, (pp. 325-339). Ibadan: Ibadan University Press.

Oderinde, A. A. (1979). Teaching to listen and speak: The development of status of speech in English language teaching. In E. Ubahakwe (Ed.) The teaching of English studies: Readings for colleges and universities, (pp. 75-91.). Ibadan: Ibadan University Press.

Osakwe, M. (2005). Welcome English... and how long English in west Delta multilingual communities? Journal of the Nigeria English Studies Association, 11 (1), 11-23.

Oyeleye, A. L. (1990). Nigeria English: A re-examination of some historical and sociolinguistic factors. Journal of Nigeria English Studies Association, 10 (2), 1-12.

Van Dijk, T. A. (1993). Principles of Critical Discourse Analysis. Discourse and Society, 4 (2), 249-283.

Retrieved July14, 2006 from http://www.discourse-in-society.org/OldArticles/Principlesofdiscourseanalysis.pdf. 